10 years ESJ

Special edition

\title{
The Project Manager "Interfaces" in a Crisis Scenario
}

\author{
Daniele Di Lorenzo, MBA, PMP, CSPO
}

Freelance, Italy

Doi: 10.19044/esj.2021.v17n30p61

\author{
Submitted: 21 June 2021 \\ Copyright 2021 Author(s) \\ Accepted: 06 July 2021 \\ Under Creative Commons BY-NC-ND \\ Published: 10 September 2021 \\ 4.0 OPEN ACCESS \\ Cite As: \\ Di Lorenzo D. (2021). The Project Manager Interfaces in a Crisis Scenario. European \\ Scientific Journal, ESJ, 17 (30), 61. https://doi.org/10.19044/esj.2021.v17n30p61
}

\begin{abstract}
A crisis induces Project Managers to use, increasingly, a specific "language" that is born from the union of two dimensions, technical-operative modalities and the mindset. The goal is to properly react to the crisis, like a pandemic scenario will. This approach directly involves the usage of "triad" (Reaction-Execution-Results) and micro-goals concepts in order to maximize the effectiveness and efficiency of the Project Manager actions within time windows. Project management is one of most important discipline in a company, especially where the project is the soul of the business and the center of the employees' dynamic. This paper focuses on the "interfaces" between project management and other company functions. It analyzes how the "language" could induce reaction behavior based on the time-constraints and micro-goal modus operandi and how the company dynamic could change its behavioral habits towards the same common company purpose: the success of projects.
\end{abstract}

Keywords: Project Manager, Interface, Crises, Triad, Unified Model, Configuration

\section{Introduction}

Project management is a "living system" within a larger "autopoietic organization" called "company" (Francisco Varela, 1987). As such it moves and follows its own linear and nonlinear internal dynamics to ensure its own survival, and that of the company, toward the success of a project. Managing projects means to apply the principles and good practices in both Adaptive and Predictive common project lifecycles. This is done using the "language" of 
Project Managers that is indissolubly composed of two interconnected dimensions, technical-operative modality and mindset (Di Lorenzo, 2021).

Following the outlook written by Akbar Azwir, the decisions of the government about the lockdown, therefore the restriction of people's movement and the enforced closing of stores and business activities, had a significant impact on projects and "as a project manager, you need to build a strong project resilience" (Azwir, 2020). Addressing the "triad" (ReactionExecution-Results) and using the micro-goals approach, the focus on the resilience could be facilitated because the focus is on the concrete and with value deliverables. The project assumes a step trend under a delivery capability perspective, and each delivery has to guarantee both the selfcontained property of deliverables and its release at a time-constrained window. Through this approach, the Project Manager deliverables are usable in the next time-window.

Therefore, the paper considers project management as the heartbeat of the company. The purpose is to move the "cone of light" to the company level and analyze the interfaces of project management discipline with other ones and functions of the company. So, the focus is on the necessary changes of the company that need to react to crisis in order to deliver, in a successful way, the projects.

\section{Sources and Methods}

This paper is an in-depth study of project management approach in a crisis scenario (Di Lorenzo, 2021) that is applied at company level. To follow this way, the paper is based on searching the same direction of previous paper, adding up new ones for specific literature. Therefore, the main international standard on project management to make explicit the "state of art" helps to highlight the importance of project concept for a company's dynamics. The web search engines (at least two) is used to identify related topics and specific publications by the usage of keywords like "crisis", "goal", "management", "configuration", "chaos", "unified model", and "integration". The purpose is to detect the opportunity to see different disciplines by a "lateral thinking" (De Bono, 1969) and to identify the new modalities of interfaces between them. The last way of deepening is the specific publication on specific company functions to understand some common characteristic like speed in delivering and what it means to "incorporate" other discipline and the feasibility of this kind of operation.

\section{Project Management Interfaces}

A company is usually a complex system that is made up of many interconnected parts. The first front-end department is, usually, the sales department whose interactions are finalized to solve specific issues. Therefore, 
the timing follows a trend like a "guerilla" (Tzu, 2013). As a result, the action is, usually, very short and efficient. The guarantee of getting the result should be maximized. The deliveries from the above department are feasible if the administrative unit uses the same timing, and all the boundary conditions are satisfied to properly react to the internal requests. Ultimately, generalizing towards a corporate vision, the goal of the front-end is to generate the basis of the birth of a project. From this specific time, a new focus is added and, consequently, there is a shift from outside view to the inside one as well. The planning department works to guarantee an appropriate schedule of all company resources to get project results. Subsequently, there is a need to highlight that this function has to plan internal and external activities. It involves proper acquiring of information about the outside environment where the resource will act. Manufacturer sites works to produce products compliant to the internal quality processes, internal timing, and costs planned expectations and external delivery constraints too. This last information shall be properly conveyed to the planning department to avoid rework and the usage of more time. The same dynamic goes for the following departments: logistic, procurement, after sales, and engineering.

The organizational structure type adopted can be functional or matrix, virtual or project-based (Project Management Institute, 2017), and anyway various units exist to support the delivery of product or service.

Consequently, all departments or company functions have to model their actions based on the "triad" Reaction-Execution-Results so as to maximize the effectiveness of each deliverable for each time within which it is allowed to act. In this way, their behavior may follow:

1. The step trend of the time (timebox). The duration of each step depends on the specific moment;

2. The self-contained micro goals as communication method between actors.

The interfaces can be better outlined if disciplines will be separate in implicit and explicit categories. Hence, these two concepts can be explained by borrowing the nomenclature and the definition of Unified Modeling Language (UML) (Grady Booch, 2005). The UML is "a general-purpose, developmental, modeling language in the field of software engineering that is intended to provide a standard way to visualize the design of a system" (Wikipedia, 2021). It includes thirteen diagrams divided into two categories for structural information and behavior. Use case diagram belongs to the last one and it models the relationship of the system using actors and use cases. Basically, there are two kinds of relationships in this kind of diagram: "extend" and "include". "Extend" is an extension of use case normal behavioral, incrementing the features by getting the services and deliverables offers from 
another use case. As such it can be used or not (under operative mode, executed or not) if all conditions for the execution are satisfied. "Include" relationship means a use case that includes the functionality described in another use case as a part of its business process flow. Therefore, this operation is, de facto, the incorporation of another use case. The actor always executes all inclusions.

Moving to the company world, the paper considers as implicit category that which provides for the include relationship, highlighting that the disciplines is one thing that is incorporated within each other. In the same way, it considers as explicit category that which provides for the extension relationship highlighting that the disciplines can be used if there is a need for the project. An example of discipline belonging to the first category is the Configuration Management (Di Lorenzo, 2018). It is so pervasive in projects and has become an integral part of project management. The main document named Configuration Management plan (Hass, 2002) is part of project management plan. It may be included in a chapter or added like an addendum. In both cases, it impacts the activities of the project team. High regulated environments, like pharmaceutical, avionics or space, are examples of this kind of incorporation. Examples of second category are disciplines like logistic, procurement, engineering, and documentation management that can be used (or not) depending on the needs at that specific moment.

The first dimension of the interface between project management and another discipline/function is the timing. The starting date and the duration of timebox could vary but is usually known in advance. Therefore, there must be a deadline within which the functions will have to getting ready to deliver their products/semi-finished product/services internally and externally. If the delivery is a tangible product like an equipment, food or hardware in general, it involves the appropriate warehouse stock capacity. The available space, as an example, becomes a distinctive element which has a competitive advantage. If the delivery is intangible like software, remote support or training, it involves the proper and necessary tools to work in remote way (virtual meeting, collaboration platform, cross-platform messaging, accessing to company resources, etc.). The best useful and integrated solution that allows access to company resource in a very fast and easy way could be a competitive advantage as well.

The second dimension is the body of the communication, which are the self-contained micro-goals. By borrowing the concepts of Increment and "Potential Releasable" from Agile world, each deliverable has to guarantee

${ }^{1} \mathrm{https} / / /$ scrumdictionary.com/term/potentially-releasable-increment/ 
high quality, good validation, and completeness ${ }^{2}$ of the delivery (Schwaber, 2017). Moreover, assuming companies are executing activities from consolidated organizational process assets (Project Management Institute, 2017) that are always valid during a pandemic, their focus would be on the extension relationship, therefore on the explicit interfaces. Each kind of microgoal should be modelled by very few and fundamental properties to check the completeness immediately, almost at a glance. The purpose of this paper does not include identifying and analyzing these properties, but each function has its own peculiarities. It involves the definition of "micro-goal completeness" which should be carried out for each function and published. Thus, this makes the interfaces to be well known.

It is important to stress that for the above to be effective with the desired results, the focus of communication should be on clarity in presentation, on transparency, and on the intent to be pursued (Organization, 2009). However, this is done while still preferring the essentiality and precision of the language to be used.

The approach shown in this paper may be used in both predictive and adaptative project lifecycles. In the first one, based on the historical series, the planning could identify an average time of work days and releasing window. On this knowledge base, it could also realize the activities company plan. For the adaptative one, there are affinities concepts like Iteration and "definition of done" ". The first has to be embedded in the available time window, resulting to more iteration in a time window. The second has to be thought of as the delivery of value for the receiver and as "final product" to guarantee the selfcontained properties. It would be more appropriate to speak of the "definition of completeness". In both lifecycles, the uncertainty of when the time window will be open is effectively cleared by the activity of "stockpiling" in anticipation of its opening.

Furthermore, the speed in micro-goal delivery is linked with the kind of company or department business activities. A service delivery has a profoundly different nature from the product ones. Usually, a service department work with action-reaction model of reply. An example of the after sales is one that delivers big quantity services and deliverables. A productbased service involves projects whose timing could be much slower. In both cases, the deliverables have to be considered as micro goals with their own properties within the time windows.

Software-automated tools are used as a link through the different department which makes the approach sustainable. Thus, this ensures the

\footnotetext{
${ }^{2}$ https://www.mountaingoatsoftware.com/blog/what-does-it-mean-to-be-potentiallyreleasable

${ }^{3}$ https://www.agilealliance.org/glossary/definition-of-done/
} 
supervision of all management steps and guarantees the interaction between them. For instance, checking the availability time for delivering, checking the completeness of micro-goals, checking the right space for "stockpiling", and tracking all steps are some of the opportunities that can be provided. All information, including the delivery, can be verified and presided "by a click".

\section{Conclusion}

Micro-goals with their own properties during the time windows refer to the interface between company departments/functions. Their characterization (properties) is very important in order to guarantee various kinds of information exchange.

The step trend of the overall company has become a systemic property and the driver is the project. For the company whose business entails the delivery of services, the applicable concepts are the same and a switch of mindset to a project approach could be effective to deliver when the time windows allow this phase.

Using a musical similitude, the company is like an orchestra. Each department is a kind of musical instrument group, arches, woodwinds, brass, percussion, harps, and soloists. The share language is the musical score, and each group has its own particularities but is necessary for the whole living system. A group is based on the ability of each member that plays using its own technicalities and emotional interpretation. Thus, the expectation of each member and each group about the results is clear. This includes the right notes at the right timing, the proper interpretation, and the right volume and the right synergy between members and groups as well as the same audience. The symphonies stand for projects and the conductor is the project management discipline that beats time using the agreed, clear, and transparent "language" that emerges from the living system named "company". Hence, it is characterized by well-known "interfaces" between several internal souls.

\section{References:}

1. Azwir, A. (2020). Managing Project in the Middle of Covid-19 Pandemic. Retrieved from MagnaQM: https://magnaqm.com/projectmanagement-articles/managing-project-in-the-middle-of-covid-19pandemic/.

2. De Bono, E. (1969). Il pensiero laterale. Come diventare creativi. BUR.

3. Di Lorenzo, D. (2018). Integrated Configuration Management. Streetlib.

4. Di Lorenzo, D. (2021). The Project Manager language in a crisis scenario. European Scientific Journal (ESJ). 
5. DoD (2001). MIL-HDBK-61A. Military Handbook Configuration Management Guidance. p.27.

6. European Centre for Disease Prevention and Control (2017). Guide to revision of national pandemic influenza preparedness plans.

7. Francisco Varela, H. M. (1987). L'albero della conoscenza . Garzanti.

8. Francisco Varela, H. M. (1991). Autopoiesis and Cognition: The Realization of the Living. Springer Science \& Business Media.

9. Grady Booch, J. R. (2005). Unified Modeling Language User Guide, The, 2nd Edition. Addison-Wesley.

10. Greenleaf, R. K. (2002). Servant Leadership: A Journey into the Nature of Legitimate Power and Greatness . Paulist Press; 25 Anvth Edition.

11. Hass, A. M. (2002). Configuration Management Principles and Practice. Addison Wesley.

12. International Organization for Standardization - ISO. (2012). ISO 21500 - Guidance on project management. ISO.

13. ISO 10007 Configuration Management. (2006, Marzo). ISO 10007.

14. Jon, M. \& Quigley, K. L. (2015). Configuration Management: Theory, Practice, and Application. CRC Press.

15. KPMG Australia (2020). COVID-19: The new reality for project and program management. Retrieved from https://home.kpmg/au/en/home/insights/2020/05/coronavirus-covid19-project-program-management-new-reality.html.

16. Lagadec, P. (1993). Preventing Chaos in a Crisis - Strategies for Prevention, Control and Damage Limitation. McGraw Hill Europe.

17. Mallak, L., Kurstedt, H., \& Patzak, G. (1997). Planning for crises in project management. Project Management Institute.

18. Maurya, A. (2012). Running Lean (Second Edition ed.). O'Reilly Media Inc.

19. National Centre for the Prevention and Control of Disease (CCM). Ministry of Health . (n.d.). NATIONAL PLAN FOR PREPAREDNESS AND RESPONSE TO AN INFLUENZA PANDEMIC. Italy.

20. Organization, W. H. (2009). Pandemic influenza preparedness and response. World Health Organization.

21. PMI (2007). Practice Standard for Configuration Management..

22. Project Management Institute. (2017). A Guide to the Project Management Body of Knowledge (PMBOK® Guide)-Sixth Edition. Pennsylvania: Project Management Institute Inc.

23. Schwaber, K. (2017). The Scrum Guide TM The Definitive Guide to Scrum: The Rules of the Game. 
24. The Agile Manifesto. agilemanifesto.org. (n.d.). Retrieved from https://agilemanifesto.org/

25. Tzu, S. (2013). L'arte della Guerra. Feltrinelli.

26. Wikipedia (2021). Unified Modeling Language. Retrieved from Wikipedia:

https://en.wikipedia.org/wiki/Unified_Modeling_Language 